Research Article

\title{
Establishing the current cover and abundance of coral in malindi marine national park
}

\begin{abstract}
Malindi Marine National Park and Reserve is a major coral reef region in Kenya that is managed by Kenya Wildlife Service. It consists of $6 \mathrm{~km}^{2}$ of shallow lagoon containing coral, sea grass and sand, which facilitate high touristic activities. In 1998, Kenyan reefs experienced between $50 \%$ and $90 \%$ coral mortality attributed to a temperature anomaly that caused global coral bleaching. Due to additional impacts from increased sediment loads from Sabaki River, the coral cover at Malindi was specifically estimated to have reduced from $35-45 \%$ (pre-bleaching) to $10-20 \%$ (post-bleaching). However, little is known about the spatial variability and recovery in Malindi coral cover over the last decade. Hence, this study sought to establish the current coral cover and identify the coral genera present of Malindi Marine Park. This was achieved using the random sampling design adapted from Paul \& Jokiel ${ }^{1}$ with a $25 \mathrm{~m}$ transect line for estimating the total cover in the three coral gardens: old coral garden, new coral garden and north reef. Also, a catalogue of coral genera occurring along the Kenyan coast was used on the sampling sites to identify the current coral genera. Results indicate that the whole park has a percentage coral cover of $21.61 \%$ with 25 coral genera encountered in the study. Porites spp was found to be the most abundant genera while Tubipora spp was the least encountered genera in the park. Though there's no significant difference among the three coral gardens, the park is seen to have high diversity in hard corals. A further study is recommended to analyze the threats posed by tourists to this important ecosystem.
\end{abstract}

Keywords: Coral reef, Cover, Abundance, Porites spp, Marine park, Malindi, Tourism, Kenya, Tubipora spp, KWS, Marine Association
Volume 3 Issue 2 - 2015

\author{
Justus Kithi Tsofa,' Grace Ngaruiya,' \\ Stanislaus M Kivai ${ }^{2}$ \\ 'Department of Plant Sciences, Kenyatta University, Kenya \\ ${ }^{2}$ Department of Conservation Biology, National Museums of \\ Kenya, Kenya
}

Correspondence: Justus Kithi Tsofa, Department of Plant Sciences, Kenyatta University, P.O. Box 43844 - 00100 Nairobi, Kenya,Tel +254723 357232, Email justintsofa@gmail.com

Received: September 27, 2015 | Published: November 24, 2015
Abbreviations: KWS, Kenya Wildlife Service; KFS, Kenya Forestry Service; ANOVA, Analysis of variance; WMA, Watamu Marine Association; MMNP, Malindi Marine National Park; MPAs, Marine Protected Areas; TARDA, Tana and Athi Rivers Development Authority

\section{Introduction}

Malindi Marine National Park and reserve (MMNP) was gazetted in 1968 making it one of the oldest Marine Protected Areas (MPAs) in Africa. It is a habitat found $100 \mathrm{~km}$ north of Mombasa in Kenya, consisting of $6 \mathrm{~km}^{2}$ of shallow lagoon containing coral, sea grass and sand. All extraction of resources, including fishing, is prohibited. It is one of two no-take zones nested within the larger Watamu-Malindi Marine National Reserve, which is $245 \mathrm{~km}^{2}$, within which traditional and sustainable fishing and extraction activities are permitted. ${ }^{2}$ The park is managed by Kenya Wildlife Service (KWS) that promotes biodiversity protection, provision of sustainable livelihoods, sustainable tourism, education and training and reducing conflicts between stakeholders of the area. ${ }^{3}$ This is because coral reefs provide food and income to coastal communities, as well as other goods and services of strategic importance to the national economy including, tourism, fisheries and coastal protection. Ecologically, corals are the main framework builders of reefs and reductions in coral abundance and associated changes in community structure result in declining biodiversity, ecological services and fisheries production. ${ }^{4}$

However, climate change driven effects increase seawater temperature, intensity and frequency of extreme thermal events and increase overall ocean acidification that often exacerbates coral bleaching and mortality. ${ }^{5,6}$ In addition, coral reefs along the
Kenyan coast experience effects from multiple stresses that are mainly associated with excessive resource extraction and utilization, eutrophication and coastal development. ${ }^{78}$ A combination of these two factors threatens existence of coral reefs which is evidenced by decline in coral cover and abundance. Coral cover is an important measure because space regulates benthic interactions on coral reefs, including competition for resources and changes in this parameter are commonly used in investigating the effects of environmental gradients. ${ }^{9}$ Second, coral cover can be a useful indicator of responses to large-scale disturbances, often linked to multiple stress factors that are non-taxa specific. ${ }^{6}$ Coral abundance is commonly described by the coral cover relative to the total area covered by other benthic biota. Consequently, several studies have revealed that the decline of corals has resulted in shifts in dominance from hard corals to macro algae and other sessile invertebrate dominated benthic functional groups in many regions of the world. ${ }^{10}$

In 1998, a wide scale temperature anomaly and recovery response study was carried out which confirmed a decline in coral cover along the Kenyan coasts. However, Malindi Marine Park and Reserve remains one major coastal coral reef region where little is known about the spatial variability in coral cover change as the last published estimates of coral cover in were made in $2002 .^{2,3,11,12}$ Since, coral cover is important to gauge the overall health and general status of a reef in relation to shifting dominance, ecological processes and economic services provided to human communities. ${ }^{9,13}$ Then there is need for updated information that can be incorporated into strategic adaptive management program and for ecological stewardship for a sustained productive coral ecosystem. Therefore, this study sought to fill this knowledge gap by establishing the current cover and abundance of coral in Malindi Marine National Park. The objectives 
of the study are: to identify coral genera in the Malindi Marine Park and to estimate the coral cover and abundance of the various genera present in the park. To enhance the results, we will further analyze for significant differences in coral genera among the coral gardens. This data will also be beneficial in predicting vulnerability of coastal reefs to future climate change.

\section{Methods}

\section{Study area}

The Malindi Marine Park and Reserve is located centrally on the Kenyan coast of East Africa. It incorporates (Figure 1) the Malindi Marine National Park, where fishing is prohibited and the Malindi Marine Reserve, which is protected, but open to fishing by artisanal fishers using traditional methods. Both areas are managed and restrictions enforced, by the Kenya Wildlife Service (KWS). Studies were undertaken in shallow ( $<2 \mathrm{~m}$ deep at low tide) back-reef environments typical of the Kenyan coast. The substratum is composed of live and dead coral skeletons interspersed with coral rubble, sand and sea grass. Massive Porites, Favidae, branching Acroporidae and Pocilloporidae frequently dominate coral communities in these sites (T. R. McClanahan, 2008). Coral communities were compared within the National Park from January-May 2015, using a random sampling design adapted from Paul \& Jokiel. ${ }^{1}$ Sampling sites were established on the shallow waters of three relatively comparable platform reefs, North Reef, old coral garden and new coral garden, located within the Marine Park (Figure 1).

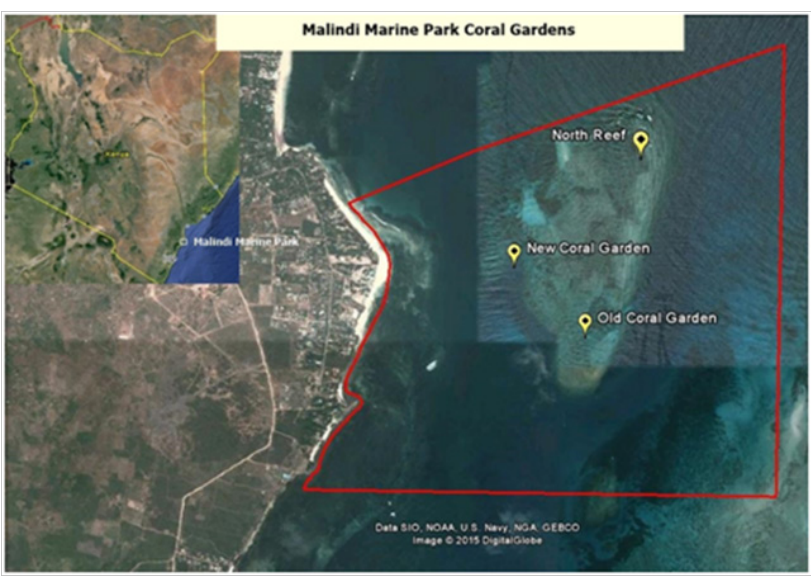

Figure I Malindi Marine Park coral gardens.

\section{Survey methods}

At the new and old coral gardens on the reef, thirteen ( 6 and 7 respectively) $25 \mathrm{~m}$ long transects were laid running parallel to the reef face, one each at $1 \mathrm{~m}, 2 \mathrm{~m}$ and $3 \mathrm{~m}$ deep. On the north reef site however, because of the site's topography and it being exposed to the strong ocean waves making docking to be difficult, only two transects could be laid, both were at $3 \mathrm{~m}$ depth. Along each transect $1 \mathrm{~m} 2$ quadrats were placed at every metre whereby visual estimates of coral cover in situ are recorded on an underwater writing slate, ${ }^{14,15}$ see Appendix 3. The quadrat frame will be divided into $100(10 \mathrm{~cm}$ $\mathrm{x} 10 \mathrm{~cm})$ smaller squares. Coral filling one of the squares occupies $1 \%$ of the frame, so that one can use the grid to estimate total area of each coral genera encountered. In my study, the quadrat will be moved successively along an entire $25 \mathrm{~m}$ transect line without overlap, encompassing a total area of $25 \mathrm{~m} 2$. The coral coverage by genera will be estimated in each frame. ${ }^{1}$

\section{Data analysis}

Areaofthequadrat $=1 \mathrm{~m} 2$.Areacoveredbyonesub-quadratis $0.01 \mathrm{~m} 2$. 15 transects of each $25 \mathrm{~m}$ length results in $375 \mathrm{~m}$ total length covered during the study with an area of $375 \mathrm{~m} 2$ If $X$ coral genera are encountered during the study covering a sum total of Y small squares having an area of $(0.01 Y) \mathrm{m} 2$

Therefore coral cover will be estimated as follows:

Coral cover estimate $=\{0.01 \mathrm{Y} / 375\} \mathrm{m} 2$.

While Simpson index was used to calculate the genera diversity:

$$
\text { Simpson Index }=\frac{\sum \operatorname{ini}(n i-1)}{N(N-1)}
$$

Where: $\mathrm{n}=$ the total number of organisms of a particular genera

$\mathrm{N}=$ the total number of organisms of all genera

One way ANOVA was used to determine if there's any significance difference in coral genera among the coral gardens.

\section{Genera identification}

Genera identification of corals was done using a printed and laminated coral genera photos occurring along the Kenyan coast as shown in appendix and 25 coral genera were observed during the study, they include: Acanthastrea, Acropora, Astreopora, Cyphastrea, Echinopora, Favia, Favites, Gardineroseris, Goniastrea, Galaxea, Goniopora, Leptastrea, Leptoria, Millepora, Montastrea, Montipora, Pavona, Platygyra, Pocillopora, Porites, Seriatopora, Stylophora, Synarea, Tubipora and Turbinaria.

\section{Results and discussion}

\section{Coral cover estimation}

The Table 1 shows the 25 coral genera encountered in the study, their abundance in terms of number of squares recorded in the quadrat among the three sites and their percentage cover in relation to the total number of squares (8102). A total of 25 genera were encountered in the study occurring within the laid transects. Transects were randomly placed within the site starting from the shallow end towards the deep ends, usually done during the low tide. Snorkeling and subsequent dives along transects in order to observe, count and record the encountered coral genera on an underwater writing slate was the main method deployed.

\section{Coral cover estimation}

Area of the quadrat $=1 \mathrm{~m} 2$. Area covered by one sub-quadrat is $0.01 \mathrm{~m} 2.15$ transects of each $25 \mathrm{~m}$ length results in $375 \mathrm{~m}$ total length covered during the study with an area of $375 \mathrm{~m} 2.25$ coral genera were encountered during the study covering a sum total of 8102 small squares having an area of $81.02 \mathrm{~m} 2$. Therefore percentage coral cover was estimated as follows:

Coral cover estimate $=81.02 \div 375$

$=0.2160533 \times 100$

$=21.61 \%$

As expressed in the table above, it was found out that Porites spp. was the most abundant genera in the park. It being a hard coral is best adapted to the Malindi marine park ecosystem as it can withstand 
the effects of sedimentation from the nearby Sabaki River and also the pressure from the human activities such as tourists visiting the park. ${ }^{12}$ According to Simpson diversity index, the park has a genera diversity of 0.12 . The park has high diversity of mainly hard corals with massive and encrusting forms; this is due to the fact that such morphologies can withstand adverse pressure from the environment and also as a result of tourist visiting these sites. Reason being their rigid stature and small heights allows them to build strong holdfasts to the substratum minimizing the chances of dislodging; their wholesome structure minimizes breakage in cases of anchorage and tourists stepping on them.

Table I Total coral genera encountered during the study

\begin{tabular}{|c|c|c|c|c|c|}
\hline \multicolumn{6}{|c|}{ Coral Genera, Cover and Abundance Data } \\
\hline \multirow[b]{2}{*}{ Genera Encountered } & \multicolumn{5}{|l|}{ Site } \\
\hline & Old & New & North Reef & Total & $\%$ Cover \\
\hline Acanthastrea & 54 & 48 & 18 & 116 & 1.43 \\
\hline Acropora & 207 & 179 & 112 & 498 & 6.15 \\
\hline Astreopora & 5 & 710 & 0 & 715 & 8.82 \\
\hline Cyphastrea & 22 & 2 & 1 & 25 & 0.31 \\
\hline Echinopora & 30 & 16 & 0 & 46 & 0.57 \\
\hline Favia & 39 & 154 & 186 & 379 & 4.68 \\
\hline Favites & 27 & 57 & $|3|$ & 215 & 2.65 \\
\hline Gardineroseris & 28 & 0 & 0 & 28 & 0.35 \\
\hline Goniastrea & 28 & 13 & 0 & $4 I$ & 0.51 \\
\hline Galaxea & 7 & 5 & 5 & 17 & 0.21 \\
\hline Goniopora & 20 & 16 & 0 & 36 & 0.44 \\
\hline Leptastrea & 168 & 152 & 0 & 320 & 3.95 \\
\hline Leptoria & 101 & $4 I$ & 0 & 142 & $\mathrm{I} .75$ \\
\hline Millepora & 0 & 297 & 614 & 911 & 11.24 \\
\hline Montastrea & 0 & 79 & 4 & 83 & 1.02 \\
\hline Montipora & 245 & 331 & 117 & 693 & 8.55 \\
\hline Pavona & 50 & 4 & 0 & 54 & 0.67 \\
\hline Platygyra & 77 & 104 & 135 & 316 & 3.9 \\
\hline Pocillopora & 177 & 363 & 35 & 575 & 7.1 \\
\hline Porites & 472 & 1185 & 409 & 2066 & 25.5 \\
\hline Seriatopora & 12 & 42 & 0 & 54 & 0.67 \\
\hline Stylophora & 65 & $|3|$ & 33 & 229 & 2.83 \\
\hline Synarea & 20 & 8 & 9 & 37 & 0.46 \\
\hline Tubipora & 0 & 4 & 0 & 4 & 0.05 \\
\hline Turbinaria & 219 & 104 & 179 & 502 & 4.3 \\
\hline
\end{tabular}

\section{Coral habitats}

\section{Old coral garden}

In the old coral garden, 22 coral genera were encountered during the study with Montipora, Turbinaria and Acropora genera (respectively) being abundant from the Porites genera (Figure 2). Total number of organisms recorded were 4041 from a total of 22 coral genera giving a diversity of 0.11 (Simpson index of diversity), this implies that it has high diversity in terms of genera. This is the most diverse habitat in Malindi Marine Park due to its location which is far from the shore, having medium utilization pressure as few tourists can reach to this site, also it is sheltered from the strong wave currents by the leopard reef to the south thus limits the adverse effects of the strong waves especially to the branching corals. ${ }^{12}$

\section{New coral garden}

Whereas in the new coral garden, 24 coral genera were encountered during the study with Astreopora being abundant in this area especially at the shallow end but reduces in abundance as one advances to the deep end with Pocillopora and Porites being more dominant. It being a highly utilized area, it experiences a lot of coral breakage especially the branching and encrusting corals explaining their low abundance in this habitat ${ }^{7}$ (Figure 3). Total Number of Organisms recorded was 2073 from 24 coral genera giving this habitat a diversity index of 0.14 (Simpson Index). High number of coral genera was encountered in this site mainly being the hard, massive corals characterized by ball- or boulder-shape and relatively slow-growing. ${ }^{10}$ Due to their stable profiles, massive corals are seldom damaged by strong wave action unless they are dislodged from their holdfasts and can withstand the pressure from the tourist activities (people standing on them, breakage due to anchorage). ${ }^{16}$

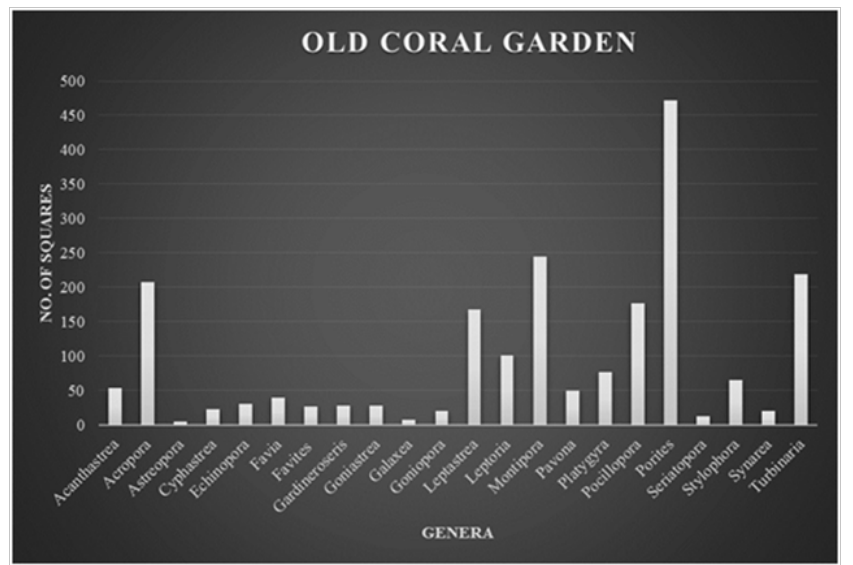

Figure 2 A histogram showing coral genera encountered in the old coral garden.

\section{North reef}

Lastly the north reef being a low use zone due to its exposure to the vast ocean and usually washed by strong waves which inhibits docking 
at this habitat. In this habitat, 15 coral genera were encountered during the study, with Millepora genera being the most dominant genera, this is due to the fact that this habitat has low disturbances caused by snorkelers and docking of boats as experienced in the new coral garden. This zone is characterized by the regeneration of corals especially the encrusting-Millepora and massive corals e.g. Favia spp. Regeneration takes place at a slower rate at this site, this being to the fact that it is washed by strong waves and it being exposed to the vast ocean waters, it is highly affected by the sediment effluents from the nearby Sabaki river, making it hard for soft corals to grow in this zone and the park as a whole. ${ }^{10}$ Total Number of Organisms recorded was 1988 from the 15 genera owing to a genera diversity index of 0.17 (Simpson Index) (Figure 4). Testing for significance differences in coral genera among the coral gardens. With an Alpha level ( $p$ value) 0.05 , There's no significance differences in coral genera among the coral gardens in Malindi Marine Park as shown in the tables in appendix 1.

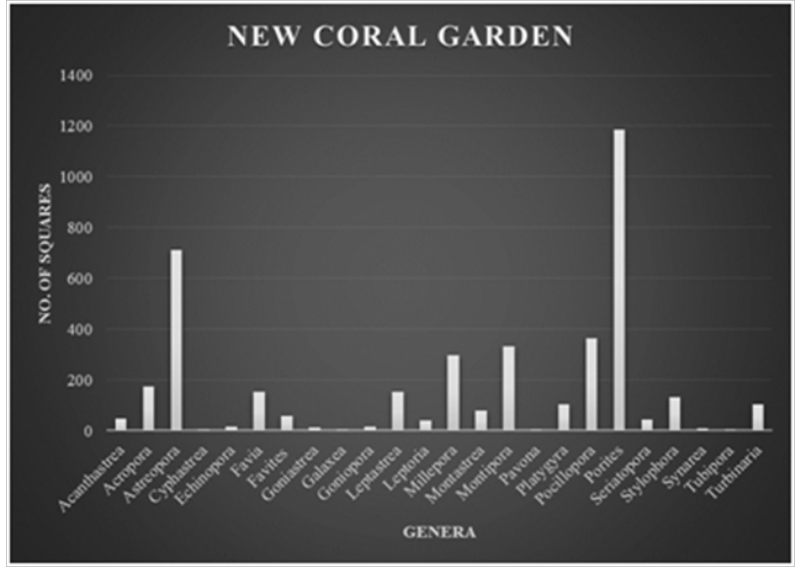

Figure $3 \mathrm{~A}$ histogram showing coral genera encountered in the new coral garden.

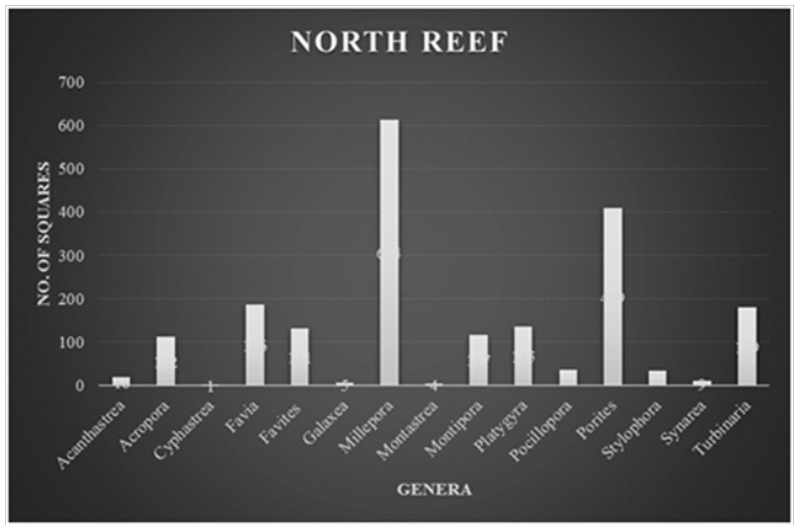

Figure $4 \mathrm{~A}$ histogram showing coral genera encountered in the north reef.

\section{Conclusion}

In terms of genera diversity, the park is seen to be of high diversity in hard corals and there's no significance difference among the three coral gardens, therefore there's need to formulate strategies which will ensure that the tourist pressure is reduced and distributed among the three sites since there's a likelihood to encounter the same genera among the three sites. A further study on the coral species should be conducted so as to add to the already known coral genera information. This report has portrayed the estimated cover and genera of corals in Malindi Marine Park, encroached upon from all sides by numerous threats. In the face of such pressures it is critical that we focus on practical, immediate responses, such as those highlighted above, to reduce and to reverse these threats. Actions now could ensure that Malindi Marine Park coral gardens remain and that they continue to provide food, livelihoods and inspiration to hundreds of millions of people now and for generations into the future.

\section{Acknowledgements}

First and foremost, we are grateful to the Almighty God who enabled and gave us the strength that sailed us through this study as well as successful training of Mr. Kithi Tsofa. This work was part of his senior thesis towards his degree program in Conservation Biology. We are also highly indebted to Willys Osore - Deputy Warden KWS Malindi Marine Park, Mr. Peter Musembi - Marine researcher from Arocha Kenya, and Steve Trott the internship supervisor at Watamu Marine Association for their support and professional guidance during this research. The results of this study would have been hard to realize without the generous field support from the KWS Malindi Marine Park and all Malindi marine park staff. Finally, we appreciate any other help received from other individuals or institutions not mentioned here towards the accomplishment of this study.

\section{Conflicts of interest}

None.

\section{References}

1. Paul L, Jokiel KS. Comparison of Methods Used to Estimate Coral Cover in the Hawaiian Islands. PeerJ 3: e954. 2005.

2. McClanahan T, Maina J, Pet-Soede L. Effects of the 1998 coral morality event on Kenyan coral reefs and fisheries. Ambio. 2002;31(7-8):543550

3. Muthiga N A. Evaluating the effectiveness of management of the Malindi-Watamu marine protected area complex in Kenya. Ocean \& Coastal Management. 2009;52(8):417-423.

4. Preskitt LB, Vroom PS, Smith CM. A Rapid Ecological Assessment (REA) Quantitative Survey Method for Benthic Algae Using Photoquadrats with Scuba. Pacific Science. 2004;58(2):201-209.

5. Fstaub. International Coral Reef Action Network: Malindi Watamu MPA Complex Demostration Site Project Final Report.WIO Project. 2004

6. Bruno JF, Selig ER. Regional decline of coral cover in the IndoPacific: Timing, extent, and subregional comparisons. PLoS One. 2007;2(8):e711

7. Sluka R, Cowburn B, Jackson C. The Impact of Watamu Marine National Park on Marine Biodiversity \& Habitats. A Rocha Kenya. 2012.

8. Burke L, Reytar K, Spalding M, et al. Raising awareness of threats to coral reefs and providing information and tools to manage coastal habitats more effectively. Reefs at Risk. World Resources Institute. 2011.

9. Dinsdale EA, Pantos O, Smriga S, et al. Microbial ecology of four coral atolls in the Northern Line Islands. PLoS One. 2008;3(2):e1584.

10. Tuda A, Omar M. Protection of Marine Areas in Kenya. George Wright Forum. 2012;29(1):43-50.

11. McClanahan TR, Ateweberhan M, Muhando CA, et al. Effects of climate and seawater temperature variation on coral bleaching and mortality. Ecological Monographs. 2007;77(4):503-525.

12. Lambo AL, Ormond RF. Continued post-bleaching decline and changed benthic community of a Kenyan coral reef. Mar Pollut Bull. 2006;52(12):1617-1624. 
13. McClanahan TR, Ateweberhan M, Omukoto J. Long-term changes in coral colony size distributions on Kenyan reefs under different management regimes and across the 1998 bleaching event. Marine Biology. 2008;153(5):755-768.

14. Dumas P, Bertaud A, Peignon C, et al. A “quick and clean” photographic method for the description of coral reef habitats. Journal of Experimental Marine Biology and Ecology. 2009;368(2):161-168.
15. Diaz-Pulido G, McCook LJ, Dove S, et al. Doom and boom on a resilient reef: climate change, algal overgrowth and coral recovery. PloS One. 2009;4(4):e5239.

16. McClanahan TR, Maina J, Starger CJ, et al. Detriments to post-bleaching recovery of corals. Coral Reefs. 2005;24(2):230-246. 